\title{
Identification of Transformer Defects via Analyzing Gases Dissolved in Oil
}

\author{
I. V. Davidenko ${ }^{a,}{ }^{*}$ and K. V. Ovchinnikov ${ }^{b}$ \\ ${ }^{a}$ Ural Power Engineering Institute, Yeltsin Ural Federal University, Yekaterinburg, 620002 Russia \\ ${ }^{b}$ CJSC PF SKB Kontur, Yekaterinburg, 620017 Russia \\ *e-mail:journal-elektrotechnika@mail.ru
}

Received August 15, 2017; revised December 25, 2017; accepted January 11, 2018

\begin{abstract}
A description of almost all the current widely used methods used for the interpretation of the results obtained in analyzing gases dissolved in oil (AGDO) is presented. In addition, a new method for identifying defect types, an algorithm for its application, and the advantages thereof over other methods are described. A technique for testing the reliability of the AGDO interpretation methods and results obtained upon testing these methods are presented. The quality of the detection provided by the considered methods has been compared with respect to various types of defects. In the course of the testing, special attention was paid to examining the issue that different methods of AGDO interpretation can identify different number of defect types. The evaluation of the quality of the methods and the testing of their reliability have been performed for a test sample containing 134 cases of transformer damage. For each case, there is a detailed description of the defect development process (the results of analyzing and testing of a transformer for the preceding period and the records in the operational documentation), as well as the results of transformer investigation, in the course of which the cause of damage done to it has been established.
\end{abstract}

Keywords: power transformers, identification of defects, analysis of gases dissolved in oil

DOI: $10.3103 / \mathrm{S} 1068371219040035$

\section{INTRODUCTION}

Analysis of gases dissolved in oil (AGDO) has been used in Russia for more than 35 years to assess the technical condition of transformer equipment (power transformers, block and converter transformers, autotransformers, oil-filled reactors). This procedure allows one to detect the development of defects in the transformer at an eaR1y stage, as well as to identify a wide range of types of defects. In spite of the fact that AGDO has been used for a long time and makes it possible to reveal up to $80 \%$ of transformer defects, accurate interpretation of AGDO results is still considered something of an art.

The evaluation of the technical condition of transformers based on the results of AGDO consists of two stages: revealing the development of a defect and determination of its nature and type. To identify a defect, one uses criteria for excessive gas concentrations and their rates of increase above permissible and maximum permissible values. The regulated values, as a rule, are found from the integral distribution function for the results of the preventive AGDO monitoring of transformer inventory at a level of 0.9 and higher.

\section{METHODS FOR IDENTIFICATION OF TRANSFORMER DEFECTS}

Methods for identification of defect types determine the character of defects (electrical or thermal), as well as the level of manifestation of a defect. The level of manifestation of thermal defects is determined by the temperature value in the defect zone. The level of manifestation of electrical defects is connected with the power, lifetime, and spatial characteristics of an electrical discharge.

International and national standards usually include several methods for identifying types of transformer defects according to the results of AGDO. To all appearances, this is connected with differing reliability in the detection of various defects using different methods. In an effort to improve the reliability of recognition of damage types, specialists in different countries are still developing novel methods and improving existing ones. In this case, the developed or improved method is "tuned" with respect to the defects characteristic of a particular inventory of transformers.

To compare the reliabilities of different methods, we have selected well-known and widely used ones. 


\section{Nomogram Method}

This method was developed by Japanese diagnosticians in the 1980s. It is existed since 2000 in the regulatory documentation of the Russian Federation [1], and it has already been used in the course of 25-30 years in the practice of the diagnostics of domestic transformers. This method is successfully used in the standards of Ukraine [2] and Belarus [3]. The method is based on the comparison of nomograms inherent in typical defects with diagrams plotted for ratios between the measured concentrations of $\mathrm{H}_{2}$ (hydrogen), $\mathrm{CH}_{4}$ (methane), $\mathrm{C}_{2} \mathrm{H}_{6}$ (ethane), $\mathrm{C}_{2} \mathrm{H}_{4}$ (ethylene), and $\mathrm{C}_{2} \mathrm{H}_{2}$ (acetylene) with respect to the maximum concentration. By comparing the nomograms of defects with the diagram of gases with respect to the maximum concentration for a transformer under study, one can choose the closest image and, thus, determine the nature of the revealed defect. The method proposes using 12 nomograms that describe eight types of defects. These are partial discharges having different intensities, sparking and creeping discharge, electric arc discharge, and heating in different temperature ranges, as well as defects that have both thermal and electrical manifestations. It should be noted that two nomograms are presented for some defects. The main advantages of the method consist in a wide range of diagnosable defect types, obviousness, usability, and the absence of undetectable states.

\section{Gas Pairs Method}

In international practice, five gas pair ratios are used to identify the type of a transformer defect as follows: (R1) $\mathrm{CH}_{4} / \mathrm{H}_{2}, \quad$ (R2) $\mathrm{C}_{2} \mathrm{H}_{2} / \mathrm{C}_{2} \mathrm{H}_{4}$, (R3) $\mathrm{C}_{2} \mathrm{H}_{2} / \mathrm{CH}_{4}$, (R4) $\mathrm{C}_{2} \mathrm{H}_{6} / \mathrm{C}_{2} \mathrm{H}_{2}$, and (R5) $\mathrm{C}_{2} \mathrm{H}_{4} / \mathrm{C}_{2} \mathrm{H}_{6}$.

The gas pairs method, which was proposed by Rogers in 1967, is based on the fact that, for each defect type, certain paired ratios between the concentrations of gases dissolved in oil are in the specified ranges. Ratios R1, R2, and R5 ratios are used in the Rogers gas pairs method. The method sets certain values of ratios R1, R2, and R5 for describing eight defect types, as well as transformers in a fault-free condition. The method recognizes four types of electrical defects, ranging from weak partial discharges (PDs) to electric arc discharges, as well as four types of thermal defects, ranging from weak heating (to $150^{\circ} \mathrm{C}$ ) to strong heating (over $700^{\circ} \mathrm{C}$ ).

The advantages of the method consist in its usability, as well as the fact that it is well-known and widely used. In Russia, the method has been used from the beginning of the use of AGDO. Different variations of the method are used in both Russian [1, 4] and foreign $[3,5,6]$ regulatory documents.

The disadvantage of this method consists in the presence of undiagnosed technical conditions of transformers, when a certain set of R1, R2, and R5 val- ues does not correspond to any of the variants presented by the gas-pairs method.

\section{Duval Triangle Method}

This method is part of international [6] and national [2] standards. The method has been known for a long time [7]; however, it is still being improved. The authors of [8] proposed six triangles for diagnosing the condition of transformers and voltage control units filled with synthetic or mineral (organic) oil. To assess the condition of a transformer filled with mineral oil, triangle 1 is used (for identifying one of the seven basic diagnoses), and triangles 4 and 5 are used to clarify these diagnoses. When comparing the reliability of defect recognition using various methods, only triangle 1 is used in this paper. Thus, in comparing the methods, it has been taken into account that the DT method can recognize the following technical transformer conditions, such as weak, moderate, and strong thermal defects; partial discharges; and lowand high-energy discharges, as well as defects of mixed type involving signs of both thermal and electrical damage. The Duval Triangle method, like the Nomogram method, is graphic, clear, and does not result in undiagnosed transformer states, but it is more difficult to use than the other graphical methods.

\section{Dornenburg Method}

This method, as well as the gas pairs method, is based on the ratios between gases dissolved in oil. In this case, ratios R1-R4 are used. The method is simple to use; however, only three types of defects can be distinguished using this method. These are heating (without separation by intensity), partial discharges, and sparking. The method has been known since 1970s and is still used in the U.S. standard [5]. The disadvantages of this method consist in a small number of recognizable defects, and in the presence of undiagnosed states.

\section{Graphic Method for Gas Pairs}

The method is based on using paired gas ratios R1, $\mathrm{R} 2$, and $\mathrm{R} 5$. In fact, this is a graphic interpretation of the GP method, but the boundaries of the relationships that determine the ranges of various defects are different. The method recognizes six types of defectspartial discharges, high- and low-energy discharges, and three gradations of heating. It should be noted that the term "high-energy discharges" in the works of foreign scientists designates electric arc discharges and strong spark discharges, whereas the term "low-energy discharges" designates creeping discharges and weak spark discharges.

Management directives [1-6] recommend additional use of the $\mathrm{CO}_{2} / \mathrm{CO}$ ratio for determining the level of manifestation of paper insulation defects. The 
Table 1. Determining the type of transformer defects according to the ensemble of characteristic gases

\begin{tabular}{|c|c|c|c|c|c|}
\hline Type of defect & $\mathrm{H}_{2}$ & $\mathrm{CH}_{4}$ & $\mathrm{C}_{2} \mathrm{H}_{6}$ & $\mathrm{C}_{2} \mathrm{H}_{4}$ & $\mathrm{C}_{2} \mathrm{H}_{2}$ \\
\hline Heating* to $300^{\circ} \mathrm{C}$ & $\mathrm{C}, \mathrm{D}$ & B & A & $\mathrm{C}, \mathrm{D}$ & $\mathrm{D}$ \\
\hline Heating* from 300 to $700^{\circ} \mathrm{C}$ & $\mathrm{D}$ & A & $\mathrm{C}$ & B & $\mathrm{D}$ \\
\hline Heating* higher than $700^{\circ} \mathrm{C}$ & $\mathrm{D}$ & B & $\mathrm{C}$ & A & $\mathrm{D}$ \\
\hline Partial discharges & A & $\mathrm{C}$ & $\mathrm{D}$ & $\mathrm{D}$ & $\mathrm{D}$ \\
\hline Low-power discharges & A & $\mathrm{C}$ & $\mathrm{D}$ & $\mathrm{D}$ & B \\
\hline Electric arc, high power discharges & B & $\mathrm{C}$ & $\mathrm{D}$ & $\mathrm{D}$ & A \\
\hline Combination of defects with prevalence of an electrical defect & $\mathrm{D}$ & B & $\mathrm{D}$ & $\mathrm{C}$ & A \\
\hline Combination of defects with prevalence of a thermal defect & C, D & A & B & $\mathrm{D}$ & $\mathrm{C}, \mathrm{D}$ \\
\hline
\end{tabular}

* Maximum heating at the location of the defect;

application of the afore-mentioned relationship to the analysis of the accuracy of the methods is not considered in this paper.

As far as the evaluation of the listed methods is concerned, it should be noted that the advantages of the nomogram method and Duval triangle method as compared to the others consist in the fact that they recognize defects that have a combined thermal and electrical character. The Duval triangle, Dornenburg, and gas-pairs methods are presented neither in the Russian management directives nor in the guidelines of Russian plants producing oil-filled equipment. In practice, there is moderate experience in using the Duval triangle method in Russia. For example, it is used in the Albatross EDIS expert diagnostic system for the evaluation of oil-filled equipment.

\section{Method of Characteristic Gas Ensembles}

This method is that created by the authors of this paper.

To identify the nature of damage, it is necessary to calculate the relative concentrations of gases $a^{i}$ using permissible concentration values $A_{\mathrm{pv}}^{i}$ :

$$
a^{i}=A^{i} / A_{\mathrm{pv}}^{i}
$$

where $A_{t}^{i}$ is the measured value for the concentration of the $i$ th gas in the analyzed oil sample, vol $\%$, and $A_{\mathrm{pv}}^{i}$ is the permissible value for the concentrations of $i$ th gas, vol \%.

In addition, an alphabetic designation should be assigned to each of the five gases $\left(\mathrm{H}_{2}, \mathrm{CH}_{4}, \mathrm{C}_{2} \mathrm{H}_{6}\right.$, $\mathrm{C}_{2} \mathrm{H}_{4}, \mathrm{C}_{2} \mathrm{H}_{2}$ ) as follows.

Letter A corresponds to the main gas for this defect with maximum relative concentration $a_{\max }^{i}$ of hydrocarbon gases and $\mathrm{H}_{2}$ under the condition $a_{\max }^{i} \geq 1$.

Letter B corresponds to a gas with a high content and its relative concentration $a^{i}$ at the second level among the gases under consideration, $a^{i} \geq 1$.
Letter C corresponds to a gas with a relative gas concentration at the third or second level among the gases under consideration, but $a^{i}<1$.

Letter D corresponds to all other gases.

Using this five-unit alphabetic classification system describing relative gas concentrations in the analyzed oil sample, one can determine the type of transformer defect using Table 1. For example, for partial discharges, such an alphabetical code can be presented as ABDDD.

If the resulting five-unit alphabetic code of the defect does not coincide with any of the alphabetic designations listed in Table 1, then the closest code among the presented defect code numbers should be found. To do this, first of all one should select defect code numbers from Table 1 according to the coincidence in the position of letter A with the code of the considered defect. If there is more than one such code number among them, then the alphabetic code should be selected that exhibits coincidence in the position of the second-most-significant letter.

For example, if the defect under consideration corresponds to the alphabetic code DABCD, then, at the first step of searching for similar defects, the DABCD alphabetic code (heating in the range from 300 to $700^{\circ} \mathrm{C}$ ) and the $[\mathrm{C}, \mathrm{D}] \mathrm{ABD}[\mathrm{C}, \mathrm{D}]$ code (combination of defects with a prevailing thermal defect) are held in reserve. At the second step, after checking the letter B position as to whether it coincides in the alphabetic code, the $[\mathrm{C}, \mathrm{D}] \mathrm{ABD}[\mathrm{C}, \mathrm{D}]$ alphabetic code remains, which unambiguously correspond to the combination of defects with a prevailing thermal defect.

\section{A TECHNIQUE OF TESTING METHODS FOR IDENTIFICATION ACCURACY OF DEFECT TYPES}

The difficulty in comparing methods consists in the fact that each method has its own set of recognizable technical condition classes that differ from each other in the number and name of defects. For exam- 
ple, the Dornenburg method distinguishes only three types of defects, whereas the Nomogram method gives 12 different of defects (which can be reduced to eight different types). Therefore, firstly, the technical condition classes of transformers intended for the recognition on the basis of AGDO have been selected (Table 2), then the types of defects determined according to each method have been correlated with the set of classes presented in Table 2.

The class with code number 1 (normal condition and natural equipment aging) includes serviceable transformers that completely perform their functions. The thermal nature of the defect is represented by the classes of technical condition with code numbers 2,3 , and 4 that differ from each other in the range of heating temperature values. The defects of electrical nature correspond to classes with code numbers 5,6 , and 7 that differ from each other in the intensity of the defect manifestation, from partial discharges to arc discharges. The class with code 6 includes two states such as sparking and creeping discharge. These defects, which differ in the causes of onset and in the character of development, are combined into one class according to the same intensity of manifestation of the electrical nature of the defects. The class with code 7 includes two states, electric arc and strong sparking accompanied by an intense heating. It is difficult to imagine an electric arc or a high-power electric discharge without heating. Combining the two types of defects in the technical condition class with one code number demonstrates that the tested methods do not necessarily need to distinguish between these states.

The classes of technical condition with code numbers 8 and 9 represent a combination of defects having electrical and thermal nature manifested with different intensity. To make a decision concerning the further operation of the transformer, it is important to know which nature of the defect prevails. It should be noted that recognition of technical condition classes 8 and 9 is not characteristic of any foreign methods, which is a general disadvantage of them. The proposed GE method identifies defects with code numbers 8 and 9, which is an additional advantage thereof.

The idea of testing consists in comparing the type of defect (the class of technical condition) from Table 2 determined by the method being used with the type of defect revealed upon the disclosure (repair) of the power transformer.

The results of comparison should be placed in the following three categories:

-full coincidence (the class code determined by the method coincides with the class code according to the results of disclosure);

- partial coincidence (the class code determined by the method coincides in the defect character and is next in the intensity of its manifestation with respect to the class code determined by the disclosure results); and
Table 2. Classes of transformer technical condition

\begin{tabular}{c|l}
$\begin{array}{c}\text { Class } \\
\text { code }\end{array}$ & \multicolumn{1}{|c}{ Name of technical condition class } \\
\hline 0 & Normal condition of the equipment or its natural aging \\
1 & Heating to $300^{\circ} \mathrm{C}$ \\
2 & Heating from $300-700^{\circ} \mathrm{C}$ \\
3 & Heating higher than $700^{\circ} \mathrm{C}$ \\
4 & Partial discharges \\
5 & Weak spark discharges and creeping discharges \\
6 & Electric arc discharge and strong spark discharges \\
7 & Combination of defects with prevalence of an electrical \\
8 & defect \\
& Combination of defects with prevalence of a thermal \\
\hline
\end{tabular}

- error (the class code determined by the method does not coincide with the class code determined by the disclosure results).

In the case of false recognition, the type of error is important:

- the used method does not recognize the manifestation level of the defect (for example, the heating temperature); and

- the used method does not distinguish between the thermal and electrical natures of the defect.

The latter kind of error is considered the crudest.

The comparison of methods should be performed using a representative sample, that represent the entire inventory of Russian transformers and all the types of technical condition classes.

For the testing, we used a database (DB) of power transformer defects collected in the Albatross expert diagnostic system for assessing the condition of oilfilled equipment (EDIS) in the course of its 25 years of operation at power engineering facilities. Each case in the test sample exhibits a history of damage development, which was reflected in the results of AGDO, in the rating characteristics of the transformer under consideration, and in the description of the event that caused the damage. The damage is described with the use of 15 classification reference books containing lists of damaged facilities, the causes of this damage, the nature of defects, the persons responsible, the consequences, etc. All the cases have been checked by experts for correspondence between the description of the damage (its completeness and accuracy) and the identification of the defect type according to the results of AGDO. After the analysis, 134 cases of transformer damage and 134 AGDO results were selected from the Albatross EDIS database corresponding to the defect nature according to its description and reflecting the culmination of its manifestation. Experts have assigned a technical condition class code to each of the selected cases according to Table 2. In 
Table 3. Statistics of defect types in the test sample of transformers

\begin{tabular}{l|c}
\hline \multicolumn{1}{c|}{ Technical condition class } & $\begin{array}{c}\text { Number } \\
\text { of cases }\end{array}$ \\
\hline Heating to $300^{\circ} \mathrm{C}$ & 5 \\
Heating from $300-700^{\circ} \mathrm{C}$ & 11 \\
Heating higher than $700^{\circ} \mathrm{C}$ & 5 \\
Partial discharges & 12 \\
Partial discharges & 16 \\
Electric arc discharge and strong spark discharges & 51 \\
Combination of defects with prevalence of an elec- & 20 \\
trical defect & 14 \\
Combination of defects with prevalence of a thermal & \\
defect & 134 \\
Total
\end{tabular}

addition, cases with mixed defect nature (technical condition code numbers 8 and 9) have been identified.

The algorithm of defect-type recognition by means of the five international methods described above, as well as by means of the GE method, was implemented with a computer with the help of the Python programming language.

In addition, each result of the AGDO sampling of damage has been analyzed using each of the six tested methods, with memorization of the revealed defect code (according to the classification presented in Table 1).

A comparison was then drawn between the technical condition code determined by the method and the code assigned by experts. The result of comparison was classified registered in the categories of Complete Coincidence, Incomplete Coincidence, and Error.

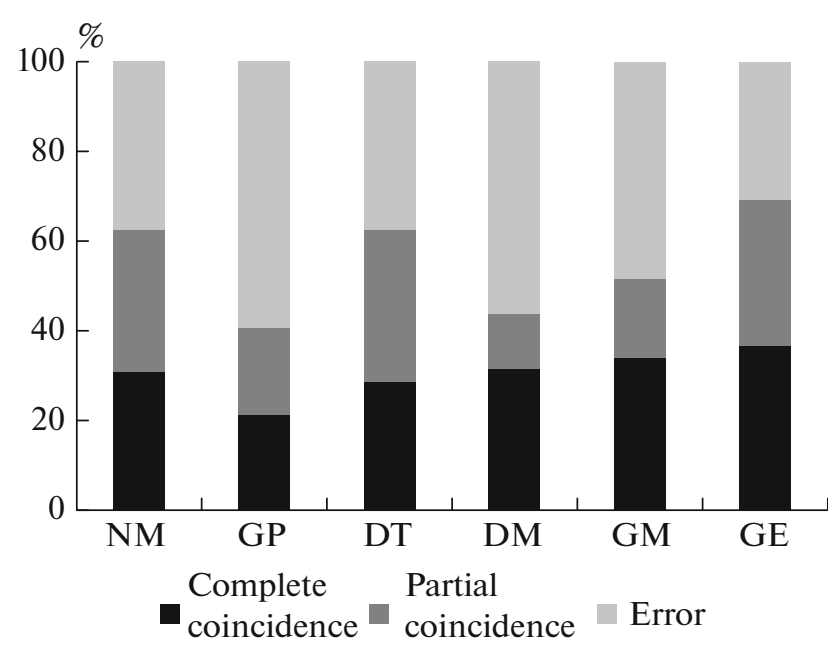

Fig. 1. Evaluation of the accuracy of the methods used.
According to the results of the comparison, the statistics of correctly and erroneously identifiable states performed using each method has been determined for each class of technical condition (type of defect).

The sample used for testing the accuracy of AGDO interpretation methods contains 134 cases of transformer damage with reliably known causes of the defects and the character of their manifestations. Experts have assigned damage-type code numbers to these defects as shown in Table 2. The statistical data on different types of damages contained in the sample are presented in Table 3 that shows that the sample unevenly covers all the types of transformer technical conditions. However, it should be noted that the total fraction of damaged windings and switching devices (SD) ranges from 60 to $70 \%$ with respect to all the cases of damage revealed in power transformers [9]. The most frequent type of defect in these units is electric arc discharge caused by various origins such as turnto-turn short circuit, and interwinding short circuit, as well as by strong sparking caused by a damaged SD. Therefore, the shift of the sample toward defects of a sparking character is quite natural and to a considerable extent reflects the actual distribution of defect types observed in the inventory of power transformers.

Figure 1 shows the testing results for the six methods with respect to the reliability of recognition of transformer defect type according to the results of AGDO. The accuracy of the methods were assessed in the basis of comparison of the type of defect determined using one of these methods with the type of defect determined by an expert according to the description of a disclosure (repair) of a transformer and the results of AGDO.

It can be seen from Fig. 1 that most methods give a complete agreement with an expert appraisal in around $30 \%$ of cases. The gas ensemble method has turned out to be the best for defect-type recognition (the diagnosis is correct in $37 \%$ of cases); all other methods yield somewhat worse results, with the exception of the gas pairs method.

To assess the recognition reliability of damage types using different methods for interpreting the AGDO results, it is necessary to take into account diagnoses that are not completely accurate, but generally correct. Such a situation can be observed if the method correctly determines the defect nature (thermal or electrical defect character), but relates the intensity of its manifestation to a neighboring class of the transformer technical condition. For example, instead of weak heating (lower than $300^{\circ} \mathrm{C}$ ), the method shows moderate heating $\left(300-700^{\circ} \mathrm{C}\right)$. In Fig. 1 , such cases are indicated "partial coincidence." If one compares the accuracy of defect determination according to the sum of complete and partial coincidence in determining the class of the technical condition, the accuracy of the gas ensemble method is 7$8 \%$ worse than that characteristic of the Duval triangle and nomogram methods. 
All the methods determine the general nature of the defect-thermal or electric-well. Weak heating has been recognized only using the graphical method of gas pairs, as well as using the method of gas ensemble. The gas pairs method is the method that most accurately identifies moderate heating. The other methods do not distinguish the moderate heating from strong heating or from a mixed-type defect such as a prevalence of heat over sparking. The Dornenburg method is an outlier in recognizing thermal defects since it does not exhibit any potential for determining the intensity of heating.

Partial discharges could not be correctly diagnosed using methods based on the ratio between the pairs of gases (gas pairs, graphic, Dornenburg methods), as well as the Duval triangle method. The gas-ensembles method has correctly revealed more than $50 \%$ of the cases of partial discharges. The remaining methods have equally revealed only a third of the total number of cases. It should be noted that, in half of cases, the methods cannot equally distinguish between the case of partial discharges and the serviceable transformer condition.

Technical condition class code no. 5 (sparking and creeping discharges) is poorly recognizes by all the methods. The gas pairs method, Duval and Dornenburg methods, and gas ensemble method never determined them correctly. Most often, this defect is identified as an electric arc discharge by means of the Duval triangle method, gas pairs method, and graphic method (30-50\% of partial coincidence). The gas ensemble method cannot distinguish sparking and partial discharges in $60 \%$ of cases.

Defect no. 6, "arc discharge and strong spark discharges," is quite well identified using all the methods (70-65\% of correctly recognized cases). The Duval triangle, Nomogram, and graphic method most often do not distinguish between electric arc and sparking (up to $20 \%$ of cases).

None of the methods (except for the gas-ensemble method) distinguish between "sparking prevalence over heating" and "strong heating" in half of cases. The gas-ensembles method has correctly revealed "sparking prevailing over heating" in $70 \%$ of cases. However, "heating prevailing over sparking" has been recognized by the GE method only in $10 \%$ of cases. It should be noted that other methods do not exhibit any ability to recognize this type of defect (code no. 8).

In general, the accuracy of the methods for identifying the defects listed in Table 1 does not exceed $70 \%$. If one considers correct recognition of a properly defined defect nature with no further identification of its severity, the share of defects recognized using the gas-ensemble method, the nomogram method, and the Duval triangle method ranges from 63 to $69 \%$.

\section{CONCLUSIONS}

The obtained result does not contradict the common opinion that AGDO can reveal more than $80 \%$ of defects in a power transformer (according to Duval, AGDO can reveal $96 \%$ of damages). When developing defects are identified on the basis of the results of AGDO by means of a test as to whether the gas concentrations and defect growth rates exceed permissible levels. In this case, the accuracy of defect-type identification is tested using the five best-known and most widely used international methods, and using the new gasensemble method for domestic power transformers.

\section{REFERENCES}

1. RD 153-34.0-46.302-00: Metodicheskie ukazaniya po diagnostike razvivayushchikhsya defektov transformatornogo oborudovnaiya po rezul'tatam khromatograficheskogo analiza gazov, rastvorennykh v masle (RD 153-34.046.302-00: Guidelines for Diagnostics of Developing Defects of Transformer Equipment by the Results of Chromatographic Analysis of Gases Solved in Oil), Moscow: Rosseti, 2001.

2. SOU-NEE 46.501:2006: Diagnostika maslonapolnennogo transformatornogo oborudovaniya po rezul'tatam khromatograficheskogo analiza svobodnykh gazov, otobrannykh iz gazovogo rele, i gazov, rastvorennykh $v$ izolyatsionnom masle (SOU-NEE 46.501:2006: Diagnostics of Oil-Immersed Transformers According to the Results of Chromatographic Analysis of Free Gases Selected from a Gas Relay, and Gases, Dissolved in Insulating Oil), Zaporizhzhia, 2006.

3. STP 09110.46.300-05: Metodicheskie ukazaniya po diagnostike razvivayushchikhsya defektov transformatornogo oborudovaniya po rezul'tatam khromatograficheskogo analiza gazov, rastvorennykh $v$ masle (STP 09110.46.300-05: Methodological Recommendations for Diagnostics of Developing Defects of Transformer Equipment by the Results of Chromatographic Analysis of Gases Solved in Oil), Minsk, 2005.

4. RD 34.46.302-89: Metodicheskie ukazaniya po diagnostike razvivayushchikhsya defektov po rezul'tatam khromatograficheskogo analiza gazov, rastvorennykh $v$ masle silovykh transformatorov (RD 34.46.302-89: Methodological Recommendations for Diagnostics of Developing Defects of Transformer Equipment by the Results of Chromatographic Analysis of Gases Solved in Oil of Power Transformers), Moscow: Soyuztekhenergo, 1989.

5. IEEE C57.104-2008: IEEE Guide for the Interpretation of Gases Generated in Oil-Immersed Transformers, Piscataway, NJ: Inst. Electr. Electron. Eng., 2008.

6. IEC 60599:2015: Mineral Oil-Filled Electrical Equipment in Service. Guidance on the Interpretation of Dissolved and Free Gases Analysis, Geneva: Int. Electrotech. Comm., 2015.

7. Duval, M., Analyse des gaz gissous: nouveaux defis, applicstions nouvelles, Electra, 1993, vol. 133.

8. Duval, M., A review of faults detectable by gas-in-oil analysis in transformers, IEEE Electr. Insul. Mag., 2002, vol. 18 , no. 3 .

9. Davidenko, I.V., Ovchinnikov, K.V., and Khalikova, E.D., Reliability analysis of 35-110 kV transformer equipment, EnergoInfo, 2013, no. 9.

Translated by O.Polyakov 